\title{
Perception of Cultural Diversity
}

\author{
İsa Erbaş \\ Department of Political Science and International Relations \\ PhD candidate, European University, Tirana, Albania \\ E-mail: isaerbas@gmail.com
}

Doi:10.5901/ajis.2013.v2n11p186

\begin{abstract}
The perception of cultural diversity is to accept and respect other nations' cultures. This means that people need to understand and recognize others' similarities and differences. The differences and similarities might be race, political implications of ethnicity, gender, economic status, nations, physical abilities, religious beliefs, political beliefs, or any other ideologies. The cultural diversity and differences emerge from the ethnic identity. People need to focus on living together with other people who are from different nations. The topic of perception of cultural diversity creates one of the most significant issues today, and the issue also may continue in the future. The cultural groupings make the whole culture in one country. People need to be acknowledged in order to develop and increase their awareness, understanding, opinions and appreciation of the different cultures. People should be aware that each culture, race and ethnicity makes a significant contribution to the world. This study begins by defining culture, cultural diversity and its influence on people and the cultural perception of people. The paper uses quantitative method with survey questionnaire. The structured questionnaire has been used to collect data.During the whole research and after the completion of the research, the researcher should abide by the ethical code of The Economic and Social Research Council (ESRC). The SPSS 16, and the Nvivo10 were used to find and analyse the collected data. The results of this paper show that there have been different views regarding the topic "perception of cultural diversity". It has been claimed that people should understand each other and go beyond simple tolerance and embrace and respect the rich cultural diversity, ethnicity and various cultures that each individual maintains.
\end{abstract}

Keywords: ethnicity, diversity, identity, society, interaction, perception.

\section{Introduction}

Culture and cultural diversity is one of the important issues which should be examined. The roles of culture and cultural diversity in peoples' life are not quite understood today. There are some reasons behind the factors why the perception of culture and cultural diversity is not understood. When we say cultural diversity, at once it comes to our minds, racism, ethnicity, color, nations, different beliefs, religions etc. "Although most people immediately think of racial and ethnic groupings whenever the topic of cultural diversity arises" (Naylor L. L., 1997, p. 211). It should be our responsibilities to recognize the fact that various cultures have various facts and realities. When we understand different beliefs of other cultures and people, then we can be able to understand ourselves and our behaviours.

The purpose of this study is to provide discussions of the perception of the cultural diversity, developing awareness and appreciation of cultural diversity in today's. Awareness of cultural diversity and acceptance the cultural diversity is very important for the stable and peaceful world. Cultural diversity is a richness of the nations and world. Sharing experiences, understanding the perception of the cultural diversity can bring comfort and peace to the different nations. We also know that culture represents ideas, habits, beliefs etc. It is also essential to know the history of culture. Cultural differences arise from traditions and religions, life philosophies and socialization processes tend to foster the asymmetric development of the independent or interdependent self (Jennifer Aakar, 2001 ). Everybody belongs to different culture, every nation belongs different cultures even there are different cultures between the same nations. Lott states that "each of us belongs to many different cultures at the same time and recognizes the consequences of this phenomenon for individual behavior and social life" (Lott, 2010, p. 9).

\section{Method of the Study}

This study has two parts. First part is about general information about culture and the perception of cultural diversity. This information has been taken from secondary sources. The information has been used as a source of the study. The 
second part of the study is an empirical case study. The data has been collected from the survey that was conducted in Albania. This study uses qualitative and quantitative methods.

\section{Culture and its Definition}

Culture, however, is more distinctly human. Cultures are traditions and customs, transmitted through learning, that form and guide the beliefs and behavior of the people exposed to them. Children learn such a tradition by growing up in a particular society, through a process called enculturation. Cultural traditions include customs and opinions, developed over the generations, about proper and improper behavior. These traditions answer such questions as: How should we do things? How do we make sense of the world? How do we distinguish right from wrong? What is right, and what is wrong? A culture produces a degree of consistency in behavior and thought among the people who live in a particular society. (Kottak, 2011, p. 5)

Laroche claims:

Culture is a group phenomenon. It is associated with a specific society or people. Culture is to this society or people what personality is to an individual. It distinguishes one society or people from another. Culture is inherited. It is transmitted from one generation to the next through a variety of means, such as arts, stories, tales, novels, movies, and education (Laroche, 2003, p. 2).

Lott states that culture in general is understood to refer to that part of our environment that is constructed by human beings to embody shared learning (Lott, 2010, p. 10). Laroche also supports Lott stating that "culture is the shared learning within a given social environment" (Laroche, 2003, p. 3). How culture is learned? Do we need any effort to learn it? We can ask such questions. Culture is learned behavior, although the learning is often out of awareness. Culture includes the society's store of knowledge, skills, attitudes, and values (Inglis, 2008, p.39).

Fisher claims :

It is shared behavior. which is important because it systematizes the way people do things, thus avoiding confusion and allowing cooperation so that groups of people can accomplish what no single individual could alone(Fisher, 1997, p. 59).

Another author also defines culture: "culture is more than just beliefs or just behaviors, just mind or matter. Anthropologists agree that culture is something that is learned, shared, integrated, and always changing" (Naylor L. L., 1997, p. 8).Naylor goes further and states that culture is learned and it is the ways of belief, behavior and the products which are shared by members within human groupings, and through cultures individuals and groups are separated from each other (Naylor L. L., 1997, p. 9).So we can say that the belief, ideas, shared things, thoughts and expectations link people who are brought in the same environment and culture. Culture is natural biological urges we share with other people and culture teaches us how to express ourselves. We have to eat, but culture teaches us when, what, and how we can eat. Everybody belongs to various cultures at different times, in different environments, and in different roles. Culture also as Jenlink claims, it is invisible that surrounds us and determines much of our identity, what we value, and how we respond to our life experiences (Jenlink, 2009, p. 183). As Smits claims that cultures shape individual identity (Smits, 2005,p.12). McSweeney also claims that we live in a culture of fluid identities a feature of modernity (McSweeney, 2004,p.162).Cultures are not the same.They differ from each other reagrding their size , construction, place, demand and degree.

According to Lott:

There are many intersecting cultures that define each of us as individual persons. Some are large such as cultures of ethnicity, gender, social class, religion, sexual orientation, age, disability, and geographical location. Some are smaller occupation, political affiliation, special talent, educational institution, unions, or clubs. Cultures differ in size and also in how they are related to (or constructed from) hierarchies of power, domination, and access to resources. Cultures differ significantly in their degree of salience and in the intensity of their influence, depending upon personal histories. And for the same person, salience and intensity of a given cultural identity will vary with the situation, the time and the place, the historical moment, social demands, anticipated consequences, personal needs, and unknown other variables (Lott, 2010, p. 7).

\section{Cultural Diversity and its Influence on People}


The term cultural diversity enable us to understand the sum of the various kinds of difference, ethnic, racial, or cultural, including their intersections or co-articulations with gender and sexuality, and also the debates, controversies, and conflicts, as well as the conviviality, warmth, and solidarity. It also enables us to understand, and interact with, cultural diversity and it also enables us to construct our cultural identities in and through the media (Siapera, 2010, pp. 6-7).

Intercultural understanding for people and the respect for different cultures are very important in order to build peace and stability among societies. Culture is an excellent concept. It has many applications among nations, communities and organizations. Do really cultures help us in our daily lives? Do cultures really ease our lives if we know others ' cultures? We can ask such questions. We can easily contact with different people through internet. We can easily travel to other countries. We live in the same world with other nations even though we do not know their languages. For this reason, we should try to learn other people` cultures in order to make our lives easier. If we do not know the people 's culture where we want to travel or live then we cannot properly understand them and we can misinterpret them. For example, I am living in Albania, there are something which are really strange to me, but if I do not know their cultures I can misunderstand them. There are also some cultures in Turkey which are strange to other people. If they do not know the Turkish culture, when they go to Turkey they can misunderstand the Turkish people. There is one proverb."When you are in Rome do as Romans do". If we do not know how people do or what their cultures are like we cannot do how they do. Cultures can be food, dress, speech, music, the way of eating, the way of talking and the way of behaving. Cultures can be affected by socioeconomic status, religion, social class, and nation of origin, region of birth, or occupation and even by geographic regions. Other's cultures enable us to evaluate our own culture. Sometimes we think that our culture is very good or the best. When we see other cultures we are actually able to compare our cultures with other cultures.We cannot criticize or blame people regarding their cultures. In every culture, the way they dress, the way they eat, the way they speak and the way they behave can be different, but we need to respect their cultures. We cannot narrow cultures. Lott claims that some people prefer to limit the concept of culture to what is learned, shared, and transmitted within large groups such as nationalities or ethnicities. (Lott, 2010, p. 13).As I stated above cultures can be everything. It is very clear that in human terms, a culture cannot develop without diversity. Culture, like nature, needs to respond to its evolving environment (Landry, 2008, p.6).

Landry goes further:

Culture is the sum of those things that define us as individuals and as members of our group and, therefore, that which distinguishes us from others. Alternatively, to think and behave with cultural awareness is to establish a means of understanding and interacting with others that may transcend perceived barriers. We may never fully know what it means to be someone other than ourselves, but if we can understand what factors and influences have made them see the world in the way they do, and we can also reflect upon how our own personal and group behaviors have been formed, we have the basis of a form of empathy upon which relationships can be built (Landry, 2008, pp.39-40).

There are many advantages of cultures. People today with proper culture, knowledge and skills are also sought by international businesses. These attribute can help identify new opportunities for international trade, while at home they help in meeting international people and tourists (Inglis, 2008, p.22). For example in Asian countries culture is crucial for the value creation of business strategy development. The local culture can be considered as a unique and distinctive value if it is properly designed, then it can be turned into business opportunities for effective marketing communication strategies (Jawad Syed, 2010, p. 33). So we can say here it is very important to cooperate with international people and various ethnic groups to increase their opportunities in order to contribute to the society. Cultures prepare us to attend to some events and not to others, to ascribe particular meanings to what we experience, observe, and learn about from others (Lott, 2010, p. 11). Jawad Syed states that "sharing values across distinct cultures is very important among diverse employees as they can create opportunities and avoid complexities in their workplace" (Jawad Syed, 2010, p. 33). Culture separates us from the rest of the world of living things. Culture distinguishes us in the animal kingdom, and it helps to define us. We as human beings create, learn, and use cultures to respond to the problems of our natural and socio cultural environments, to control us, and even to change us (Naylor L. L., 1997, p. 3).For example, culture also tells us how to greet one another, when it is appropriate to call someone on the phone, and what topics we should avoid in conversations. In the professional world, culture tells us what time people will likely come to work and leave, what we should do is to help others, when it is appropriate to ask for help, what we should do is to achieve our professional goals, and so on (Laroche, 2003, p. 25).

Lott states:

It is within our (various) cultures that we have practiced and learned how to behave, and what to believe and feel, in accord with prescriptions and proscriptions that were transmitted to us across time from significant others. Cultural 
influences continue to mold the specifics of development, beginning before birth, influencing subtle and also clear and obvious ways of doing things (Lott, 2010, p. 13).

In some cultures people whenever see each other they should greet each other with warm respect and use good words, but in some other cultures it is not much important. So we need to learn the cultures in order to be respected by other people. Lessem claims that "culture bridges the individual and the external worlds, one department and another, the conscious and subconscious minds, corporate strategy and corporate culture" (Lessem, 1998, p. 95). Kottak also claims that "Culture is an environmental force that affects our development as much as do nutrition, heat, cold, and altitude. Culture also guides our emotional and cognitive growth and helps determine the kinds of personalities we have as adults" (Kottak, 2011, p. 4).According to Landry:

The confident secular humanist view proposes a set of civic values and rules of engagement, which include: providing settings for a continually renewing dialogue across differences, cultures and conflicts; allowing strongly held beliefs or faiths expression within this core agreement; and acknowledging the 'naturalness' of conflict and establishing means and mediation devices to deal with difference. It seeks to consolidate different ways of living, recognizing arenas in which we must all live together and those where we can live apart. It generates structured opportunities to learn to know the 'Other', to explore and discover similarity and difference (Landry, 2008, p.9).

There are many advantages of cultural diversity. Cultural diversity firstly, helps people or communities how to live together. Secondly, it helps interact with each other. When people interact with each other; the interaction will bring peace and happiness. The most successful interactions occur when nations from various backgrounds share experiences. When we know their cultures we learn how the people behave, how they communicate and we learn what they like or dislike. We avoid misunderstanding different nations. In some countries there are many different nations that live without any conflicts. Various cultures is a richness of communities, it is a color of different nations. Cultural diversity's due must be conducive to peace within countries, between regions, and throughout the world (Stenou, 2004). Stenou also claims that cultural diversity can conduct peace within countries, between regions, and throughout the world (Stenou, 2004).James Lynch draws our attantion to the fact that multiculturalism is a sensitive issue. He claims that " all societies have become multicultural, and it is vital to prevent social conflict through an education that fosters understanding and respect for cultural diversity, as well as communication and cooperation between persons of different origins" (James Lynch, 1992, p. 169). It is very significant to learn other nations' cultures. We need to learn how to communicate with other nations, particularly nowadays, communicating with diverse communities from different cultures means to strengthen democracy and active citizen participation, encourage respect for human rights and cultural diversity and work on human capital development offers a solid foundation for the improvement of living conditions (Xhavit Rexhaj, 2010, p. 10).

\section{Cultural Perception of People}

Every person has his or her cultural perception .There is diversity within cultures and there is also diversity between cultures. Cultural perception enables us to understand different cultures and it also enables us to understand social problems. There are some ways of learning cultures. Sometimes cultures are taught directly. For example, parents teach their children to say "thank you" or "sorry" when someone gives them something or when they make mistakes. Cultures are absorbed unconsciously and they are also transmitted through observation.

Children pay attention to the things that go on around them. They modify their behavior not just because other people tell them to but as a result of their own observations and growing awareness of what their culture considers right and wrong. Culture also is absorbed unconsciously. North Americans acquire their culture's notions about how far apart people should stand when they talk not by being told directly to maintain a certain distance but through a gradual process of observation, experience, and conscious and unconscious behavior modification. Regardless of their genes or their physical appearance, people can learn any cultural tradition (Kottak, 2011, p. 27).

James Lynch states that 'intercultural' education seeks to sensitize the children to the respect of diversity, to tolerance and solidarity. It is designed to prepare future citizens for a harmonious life in multicultural societies" (James Lynch, 1992, p. 174).Children should be taught well regarding the cultural similarities and differences.

I conducted a survey in Albania about cultures. This survey took about 7 months' started in December, 2012 and finished in June, 2013. I conducted this survey by asking 716 people in different Albanian cities mainly: Tirana, Shkoder, Kaveje, Kruje, Lushnije and Durres. I tried to conduct this survey with people, particularly, who were studying in the universities or who graduated from the universities. The survey questions were completed by different group of people such as: teachers, doctors, academicians, politicians, lawyers, businessmen, economists, people who work private 
sectors and also some other profession groups. The main goal about this survey was to find out the Albanian people's perception and thoughts about culture. The survey includes $50.08 \%$ female and $49.02 \%$ male. The education percentage of these respondents is $22.3 \%$ secondary education and $77.7 \%$ university education. This survey was conducted face to face interview with different age groups starting from 18 to 60.Each survey took about 3-4 minutes. I asked the people two questions regarding the culture.

Figure 1. Which of the followings do you think Albania has made great progress since 1991? (Frequency)

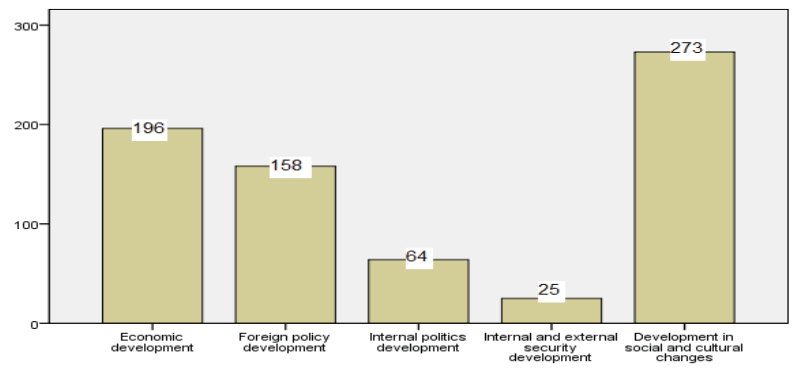

Figure 2. Which of the followings do you think Albania has made great progress since 1991? (Percent)

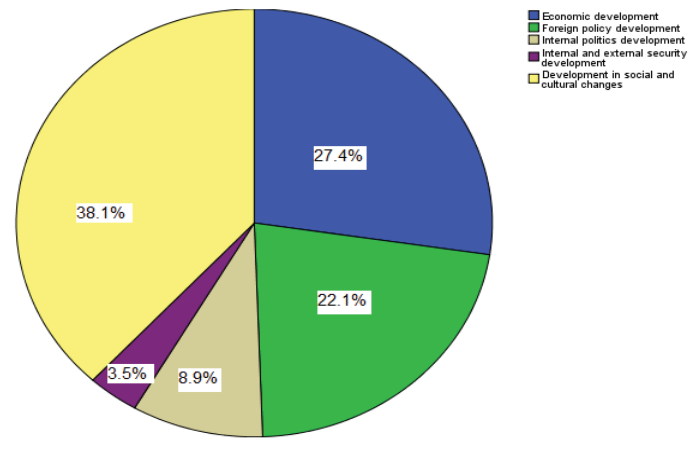

It is shown in the figure 1 and 2 that majority of the respondents, 38.1 percent or 273 out of 716 , think that Albania has made great progress in development in social and cultural changes since 1991.This survey proves that people are interested in cultural development.

Figure 3. What is the influence of Albanian people living abroad on the Albanian foreign policy? (Frequency)

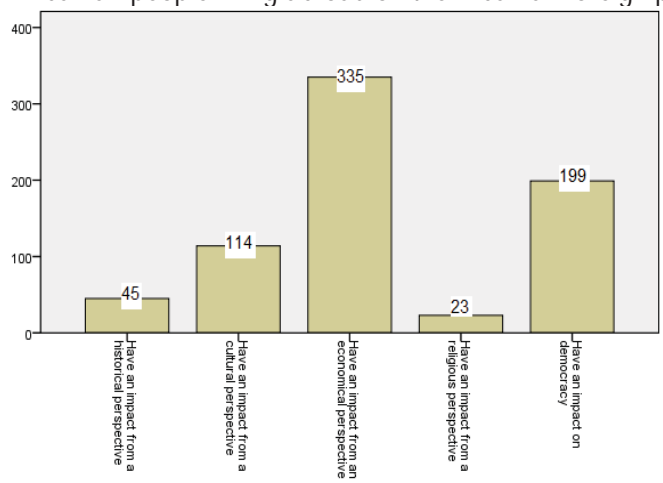

Figure 4. What is the influence of Albanian people living abroad on the Albanian foreign policy? (Percent) 


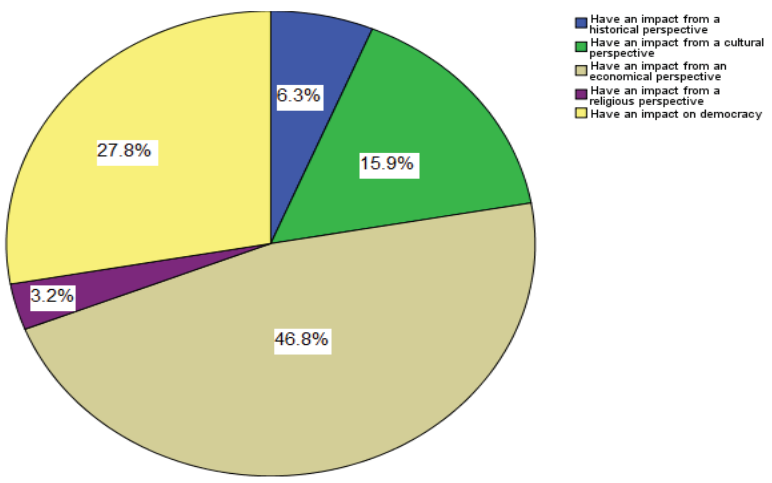

It is shown in the figure 3 and 4 that many respondents, 15.9 percent or 114 out of 716, think that Albanian people who live abroad have an impact on the Albanian foreign policy from a cultural perspective. This survey shows that not only people learn the culture where they live; they have also impact on their own country.

Cultures establish more or less homogeneous set of beliefs and assumptions by which everyone can project their perception and expectations onto other people without thinking about it. These perception and expectations keep societies together; they mainly facilitate interaction and cooperation (Fisher, 1997, p. 46).Our cultures and cultural changes influence the ways in which we perceive nature, human nature, and the natural. If culture is understood as an ethnicity, it may have perceived cultural similarities and differences in a society or nation which can be expressed in peaceful multiculturalism or in discrimination or violent interethnic confrontation. For the mentioned reasons culture can be both adaptive and maladaptive. The perception of cultural differences may have dangerous and bad effects on social interaction (Kottak, 2011, pp. 28-29). Through positive and intercultural dialogues, cultural diversity is an essential for diverse cultural societies. We cannot find any culture which is perfect for us, but we can learn something from each culture and we can contribute something to each culture. Cultures broaden our minds and our abilities. Every country and every nation has different cultures. For this reason the people's awareness should be increased about the diversity and differences of cultures.

\section{Result of the Study}

I made a survey with 716 Albanian people about culture. According to the survey, the people state they are all aware the importance of cultures. We need to learn others` cultures. When we learn other nations' cultures then we can be able to learn our own cultures and we can compare others' cultures with our culture. We also need to understand the importance of cultures. When we learn others ' cultures we can find it easy to live with other people and we can face less conflict with others.

The results of this study show that there are different views regarding the cultural diversity .By this research we have come into conclusions that people gain experience and knowledge through cultural diversity. Cultures are the shared learning within a given social environment. When we are aware of the importance of cultural diversity, when we understand and interact with others we may break the barriers among nations. Cultural diversity is a richness of a state. We learn various things and cultures every day from our friends, neighbours and surroundings. If we have backgrounds and life experiences of cultural diversity we can see problems and find solutions to them from a variety of perspectives. Cultures can be interacted widely. The most successful and important interactions occur when nations from various backgrounds share experiences.

\section{Discussion of the Result}

It is obviously observed that people discuss and talk about cultural diversity every where. This study shows that thepeople are intersted in cultural diversity.People go to other countries to study and also to study, interact with people and learn their cultures.People, especially new generation have to be taught at the very early ages about cultural diversity. According to the research and survey I have found out that people are aware of the importance of cultural 
diversity. For the future stability and peace among nations every country needs to provide people with information about cultural diversity.

\section{Conclusion}

Intercultural dialogue results from the diverse cultures. If cultures are perceived as a kind of ethnicity we can say there is hardly any peace and stability. Peace is and stability needed everywhere. People need to learn to live with different nations in one place. We should respect each other's culture. There is a fact that cultural diversity is an opportunity for fruitful dialogues among nations. Since we think that cultural diversity is a richness of the world, we need to find the ways how to interact more with other nations. We need to use this opportunity in order to develop our intercultural dialogues. We should find different methods towards different cultures and accept them as they are. Honest and sincere dialogue and interaction should be established among societies in order to learn various cultures. As I have said before, cultural diversity is very important for culturally diverse societies. There are many things that can be learned from each culture and many things can be contributed to each culture. Nowadays cultural exchange and cultural tolerance is becoming more and more important towards various nations. If we believe the strength of cultural diversity and its advantages for the world peace, then we and the new generation will have a good and prosperous life in the future.

\section{References}

Fisher, G. (1997). Mindsets, The Role of Culture and Perception in International Relations. Yarmouth: Intercultural Press.

Inglis, C. (2008). Planning for cultural diversity. Paris: UNESCO.

James Lynch, C. M. (1992). Cultural Diversity and the Schools. London: The Falmer Press.

Jawad Syed, M. F. (2010). Managing Gender Diversity in Asia. Northampton: Edward Elgar Publishing Limited.

Jenlink, P. M. (2009). The Struggle for Identity in Today`s Schools, Cultural Recognition in a Time of Increasing Diversity. Lanham: Rowman \& Littlefield Education.

Jennifer Aakar, B. S. (2001 ). Culture Dependent Assimilation and Differentiation on the Self. Journal of Cross-Cultural Psychology, Vol. 32 No.5, $561-576$

Kottak, C. P. (2011). Cultural Anthropology. New York: McGraw-Hill.

Landry, P. W. (2008). The Intercultural City. London: Earthscan.

Laroche, L. (2003). Managing Cultural Diversity in Technical Professions. London: Butterworth-Heinemann.

Lessem, R. (1998). Management Development through cultural Diversity. London: Routledge.

Lott, B. (2010). Multiculturalism and Diversity. Oxford: A John Wiley \& Sons, Ltd., Publication.

McSweeney, B. (2004). Security, Identity and Interests,A Sociology of International Relations. Cambridge: Cambridge University Press.

Naylor, L. L. (1997). Cultural Diversity in the United States. Westport: Greenwood.

Siapera, E. (2010). Cultural Diversity and Global Media. Oxford: Wiley- Blackwell.

Smits, K. (2005). Reconstructing Post-Nationalist Liberal Pluralism From Interest to Identity. New York: Palgrave Macmilan.

Stenou, K. (2004). Cultural Diversity and Globalization ,The Arab-Japanese Experience, a Cross-Regional Dialogue. UNESCO (pp. 1140). Paris: UNESCO.

Xhavit Rexhaj, M. M. (2010). Mapping policies and practices for the for the preparation of teachers for inclusive education in contexts of social and cultural diversity. Country Report for Kosovo : European Training Foundation. 